\title{
Camouflage of sea spiders (Arthropoda, Pycnogonida) inhabiting Pavona varians
}

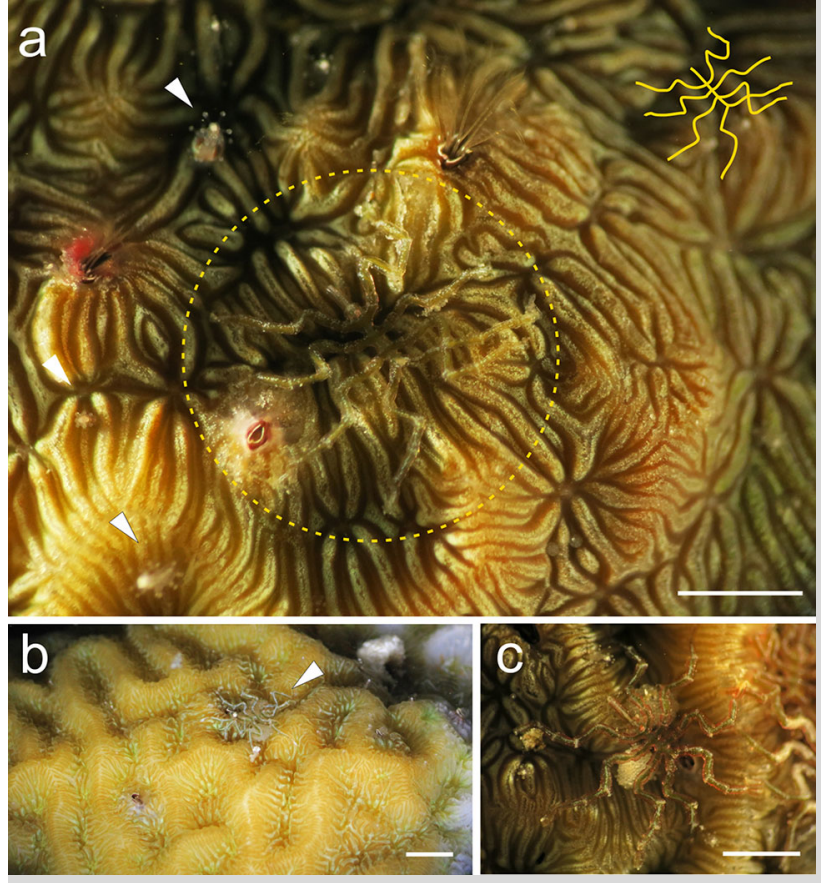

Fig. 1 a Endeis sp. on Pavona varians displaying extreme camouflage (dashed line); b Endeis sp. carrying eggs; c close-up of Endeis sp. Scale bars: 2 mm
Despite the controversial phylogenetic position of the Class Pycnogonida, sea spiders account for an enormous diversity of species, inhabiting all benthic marine habitats worldwide. Although they have been observed on coral reefs, few sea spider species have been reported in association with coral reef organisms and even more rarely with reef-building corals (Stella et al. 2010). In a biodiversity study in 2017, various individuals of Endeis sp. were observed on Pavona varians colonies inhabiting the coral reefs surrounding Magoodhoo Island, Maldives. The sea spiders were generally observed dwelling on and between the corallites of $P$. varians, with each leg overlapping the natural long septa of the coral. Their motionless behaviour rendered them completely undetectable without careful inspection (Fig. 1). The nature of the relationship between the corals and sea spiders on this reef is not clear, although Arango (2001) previously reported feeding behaviour by sea spiders on fire corals. Moreover, sea spiders are also known to be parasitically associated with several organisms, including at least 20 hydrozoan species, in which the gastrovascular cavities of the polyps are used for the development of the pycnogonid protonymphs (Bettim and Haddam 2013). It is likely that Pavona-inhabiting sea spiders, as well as other coral cryptobenthic associates, are commensals, just looking for shelter among corallites or coral tentacles; however, the co-occurrence of coral-associated hydrozoans of the genus Zanclea (Fig. 1a, arrowheads) and egg-carrying individuals on all observed $P$. varians colonies (Fig. 1c) suggests many possible scenarios. There have been few research efforts investigating small coral-associated invertebrates with extremely successful cryptic strategies, such as these pycnogonids, and it is likely that this has led to the lack of observations regarding this association. To our knowledge, this finding represents the first record of sea spiders observed on reef-building corals in the Indian Ocean and serves to improve the scarce knowledge of coral-associated sea spiders.

\section{References}

Arango CP (2001) Sea spiders (Pycnogonida) from the Great Barrier Reef, Australia, feed on fire corals and zoanthids. Memoirs of the Queensland Museum 46:656

Bettim AL, Haddad MA (2013) First record of endoparasitism of Pycnogonida in Hydrozoan polyps (Cnidaria) from the Brazilian coast. Biota Neotropica 13:319-325

Stella JS, Jones GP, Pratchett MS (2010) Variation in the structure of epifaunal invertebrate assemblages among coral hosts. Coral Reefs 29:957-973

S. Montano (iD $(\bowtie) \cdot$ D. Maggioni

MaRHE Center (Marine Research and High Education Center), Magoodhoo Island, Faafu Atoll, Republic of Maldives

e-mail: simone.montano@unimib.it

Received: 19 September 2017 / Accepted: 9 November 2017/Published online: 15 November 2017

Coral Reefs (2018) 37:153

(C) Springer-Verlag GmbH Germany, part of Springer Nature 2017 